\title{
The Effect of Geogebra on Students' Conceptual and Procedural Knowledge: The Case of Applications of Derivative
}

\author{
Mehmet Fatih Ocal ${ }^{1}$ \\ ${ }^{1}$ Department of Mathematics and Science Education, Ağrı İbrahim Çeçen University, Ağrı, Turkey \\ Correspondence: Mehmet Fatih Ocal, Department of Mathematics and Science Education, Ağrı İbrahim Çeçen \\ University, Merkez, Ağrı, Turkey. Tel: 90-472-215-2038. E-mail: fatihocal@gmail.com
}

Received: March 24, 2017

Accepted: April 25, 2017

Online Published: May 2, 2017

doi:10.5539/hes.v7n2p67

URL: http://doi.org/10.5539/hes.v7n2p67

\begin{abstract}
Integrating the properties of computer algebra systems and dynamic geometry environments, Geogebra became an effective and powerful tool for teaching and learning mathematics. One of the reasons that teachers use Geogebra in mathematics classrooms is to make students learn mathematics meaningfully and conceptually. From this perspective, the purpose of this study was to investigate whether instruction with Geogebra has effect on students' achievements regarding their conceptual and procedural knowledge on the applications of derivative subject. This study adopted the quantitative approach with pre-test post-test control group true experimental design. The participants were composed of two calculus classrooms involving 31 and 24 students, respectively. The experimental group with 31 students received instruction with Geogebra while the control group received traditional instruction in learning the applications of derivative. Independent samples t-test was used in the analysis of the data gathered from students' responses to Applications of Derivative Test which was subjected to them before and after teaching processes. The findings indicated that instruction with Geogebra had positive effect on students' scores regarding conceptual knowledge and their overall scores. On the other hand, there was no significant difference between experimental and control group students' scores regarding procedural knowledge. It could be concluded that students in both groups were focused on procedural knowledge to be successful in learning calculus subjects including applications of derivative in both groups. On the other hand, instruction with Geogebra supported students' learning these subjects meaningfully and conceptually.
\end{abstract}

Keywords: applications of derivative, conceptual knowledge, Geogebra, procedural knowledge, teaching math

\section{Introduction}

With the advent of technology, various readily available technological tools were designed and used for educational purposes (Heid, 1997). From the perspective of teaching mathematics, technologies such as educational software, interactive whiteboards and computers are integrated into classroom use to provide more comprehensive learning opportunities for students (Öçal \& Şimşek, 2017). As software, Computer Algebra Systems (CAS) and Dynamic Geometry Environments (DGE) are considered as two important examples among modern educational technologies especially for teaching mathematics (Botana \& Valcarce, 2001). Both software categorized as CAS and DGE have wide variety of applications in teaching mathematics and helpful tool for students' understanding of mathematics subjects. Advantages of effective use of any of these software in classroom environment were mentioned in the previous literature excessively (e.g., Artigue, 2002; Erbas \& Yenmez, 2011; Furner \& Marinas, 2007; Healy \& Hoyles, 2002; Kabaca, 2006; Öçal, 2017). For example, CAS software packages such as Derive, Mathematica and Wolfram Alpha enable students to do mathematical computations with mathematical symbols. Some examples also provide students with graphical or tabular demonstrations of algebraic computations and step-by-step solutions for them (Kabaca, 2006). These software packages provide students with enriched learning environments to discover mathematical ideas and theories (Artigue, 2002; Kabaca, 2006). On the other hand, software packages with the features of DGE such as Cabri Geometry, Geometer's Sketchpad and Cinderella are useful tools for students to visualize mathematical structures, concretize its abstract nature, and construct link between algebra and geometry (Hohenwarter \& Jones, 2007). Considering the fact that same mathematical structure may vary or be perceived differently in different contexts, the properties of DGE software packages enable students to see the differences and comprehend the reason-result relations in various contexts, and observe them from multiple perspectives, especially with its 
dragging property (Hohenwarter \& Jones, 2007). They also allow students to explore both algebraic and geometric representations of the same mathematical structures (Hohenwarter \& Fuchs, 2004). Therefore, they can make connections between different forms and explore how any change in one form of any mathematical structure influence its other forms. In addition, students can do modeling activities, so they can construct and understand relation between real life and abstract mathematical structures and concepts studied (Hohenwarter \& Fuchs, 2004; Pierce \& Stacey, 2011).

In recent years, a software package called Geogebra is widely used in mathematics classrooms (e.g., Aydos, 2015; Öçal, 2017; Shadaan \& Leong, 2013; Tatar \& Zengin, 2016). The prominent feature of Geogebra is that it combines the properties of both CAS and DGE in a single software package (Hohenwarter \& Fuchs, 2004). This software allows users to see the algebraic, graphical and spreadsheet forms of any mathematical objects at the same time (Hohenwarter \& Jones, 2007). Therefore, using Geogebra promotes students' meaningful and conceptual understanding of intended mathematics topics. In addition, mathematics education researchers provided evidences that effective use of Geogebra supported and had positive impact on students' conceptual understanding and performances in wide variety of mathematics topics including geometry (e.g., Samur, 2015), analytic geometry (e.g., Tatar, 2012; Zengin \& Tatar, 2014), algebra (e.g., Healy \& Hoyles, 2002), and calculus (e.g., Aydos, 2015; Tatar \& Zengin, 2016; Kepceoğlu, 2010).

This study specifically interested in the applications of derivative which is one of the topics covered in calculus. Here, the calculus is mainly perceived as a basis for advanced mathematics topics (Mahir, 2009). Considering the applications of derivative, solving max-min and related-rate problems, problems, finding tangent lines of a function at a given point and interpretation of graphs of functions and/or their derivatives constitute the content in calculus courses. Comprehending the applications of derivative topic plays key role for further mathematics courses and other interdisciplinary areas (Tall, 1993). For example, those who comprehend interpretation of graphs of functions and their derivatives are expected to be successful in analytic geometry and complex analysis courses. On the other hand, the related-rates and max-min problems are focusing on the concept of change. Along with the interpretation of graphs of functions, learning them may be helpful for students to construct relations in interdisciplinary courses such as physics (Meltzer, 2002). Although it is of great importance for students to understand applications of derivative in calculus, various studies indicated that students experienced difficulties in learning them (e.g., Mahir, 2009; Tall, 1993; Tatar \& Zengin, 2016). Taking the importance of this topic, higher order thinking skills are necessary to meaningfully understand the contents. As known, students need to understand how the functions are constructed and know the interrelation among these function, their derivatives and their graphical representations. They also need to interpret the meaning of and make justifications from the algebraic or graphical representations of the functions and/or their derivative (Hohenwarter \& Fuchs, 2004). However, students consider that the concepts and applications covered are abstract and include various formal definitions and proofs (Tall, 1993). In addition, they are struggling with relating the algebraic expressions or equations with their graphical, tabular or other representations. For these reasons, students prefer to memorize the solutions steps for specific problems and follow the procedures, instead of trying to understand the calculus topics and concepts meaningfully and conceptually.

As stated in Aspinwell and Miller's (1997), Mahir's (2009) and Tatar and Zengin's (2016) studies, one of the reasons that students experience difficulties in learning calculus stems from the insufficiency of conceptual knowledge. In addition, since students perceives the computations done in solving calculus problems as first priority, they mainly focus on procedural knowledge (Aspinwell \& Miller, 1997). In this study, the focus was on students' conceptual and procedural knowledge in learning applications of derivative topic. Therefore, the concepts of conceptual and procedural knowledge should be defined. Based on Star's (2005) definitions, the conceptual and procedural knowledge refer to the following meanings in this study. "The term conceptual knowledge has come to encompass not only what is known (knowledge of concepts) but also one way that concepts can be known (e.g., deeply and with rich connections)" (p. 408). Therefore, the conceptual knowledge involves the students' understanding of the interpretation of the concepts and the relations among these concepts (Arslan, 2010). For conceptual knowledge, understanding the concepts and the relations among them is essential. On the other hand, Star (2005) defined the term procedural knowledge that “... indicates not only what is known (knowledge of procedures) but also one way that procedures (algorithms) can be known (e.g., superficially and without rich connections)" (p. 406). Therefore, the procedural knowledge involves the rules, the algorithms and operational procedures to be followed in fulfilling mathematical tasks (Yanık, 2016). Not giving attention to conceptual knowledge and relying heavily on procedural knowledge may only have limited effect on students' success in learning the topics studied. In fact, there should be balance between conceptual and procedural knowledge in learning a specific topic, because conceptual and procedural knowledge develop simultaneously 
and each knowledge type interact with each other. The improvement in one type of knowledge influence the other one (Rittle-Johnson, Siegler, \& Alibali, 2001). As Rittle-Johnson et al. (2001) indicated that "increase in one type of knowledge lead to gains in the other type of knowledge, which in turn lead to further increase in the first" (p. 347), students need to have both type of knowledge to be successful in learning any topic. From this perspective, it can also be inferred that there is no precise distinction between the conceptual and procedural knowledge. For students, one type of knowledge may include parts of other type of knowledge or vice versa (Star, 2005; Yanık, 2016). However, one type may be dominant.

In order to make calculus students have balanced procedural and conceptual knowledge and feel confident in learning the calculus topics, especially the applications of derivative, procedurally and conceptually, therefore, to be successful in learning calculus, there are various ways of instructional methods. Considering the applications of derivative in calculus, numerous researchers indicated that Geogebra assisted instructions had significant influence on students' achievements. In the experimental studies from different grade levels, teaching mathematics with Geogebra has positive influence on students' achievements on different mathematics topics (e.g., Dikovic, 2009; Shadaan \& Leong, 2013; Samur, 2015; Zengin \& Tatar, 2014; Tatar, 2012) compared to those receiving traditional/textbook-based instructions or interventions. There are also evidences that Geogebra assisted instructions supports students' conceptual and procedural knowledge on different courses, including applications of derivative in calculus. For example, Aydos (2015) investigated the influence of teaching mathematics with Geogebra on gifted high school students' conceptual understanding of limit and continuity subjects. It was found that experimental group students who received intervention with Geogebra had better scores in the test measuring their conceptual knowledge than those who received traditional instructions. Similar study with the same subjects was also conducted by Kepceoğlu (2010) for pre-service mathematics teachers. Regarding students' conceptual understanding, experimental group students receiving instruction with Geogebra outperformed than those who received traditional instruction. Similarly, Tatar and Zengin (2016) found that first grade university students' conceptual understanding on definitive integral was higher in the experimental group which the instruction was mainly done with Geogebra. Lastly, Zulnaidi and Zakaria (2012) investigated the effect of Geogebra on students' achievements regarding their conceptual and procedural knowledge on functions. When their conceptual and procedural knowledge are taken into account, students in the experimental group achieved significantly higher scores than those in control group.

The studies in the literature mainly focused on students' achievements in different subjects. It was also observed that the studies investigating the effect of Geogebra on students' conceptual and procedural knowledge were limited and mainly focusing on their conceptual knowledge. From this perspective, this study aims to investigate the effect of Geogebra aided instruction on students' performance in geometric meaning of derivative and its applications (applications of derivative) topic. With this aim, this study compared the effect of instructional activities using Geogebra on students' performance regarding their conceptual, procedural knowledge and overall scores with the performance of students receiving instructions without Geogebra.

\subsection{Hypotheses of the Study}

According to the aims proposed, the null hypotheses were as follows:

$\mathrm{H}_{01}$ : There is no statistically significant difference between experimental (receiving instruction with Geogebra) and control (receiving traditional instruction) group students' conceptual knowledge scores in the subject of applications of derivative.

$\mathrm{H}_{02}$ : There is no statistically significant difference between experimental and control group students' procedural knowledge scores in the subject of applications of derivative.

$\mathrm{H}_{03}$ : There is no statistically significant difference between experimental and control group students' overall scores in the subject of applications of derivative.

\section{Method}

This study adopted the quantitative approach with pre-test post-test control group true experimental design (Fraenkel \& Wallen, 2006). This design is widely used in educational experimentation by investigating and seeking for possible reasons of the events or phenomenon studied (Karasar, 2009). This design requires randomization during constituting the groups. Its power is obvious that it helps researchers to control the factors that may mislead the results of the study over the control and experimental groups (Cohen, Manion, \& Morisson, 2000). In addition, all threats related to internal validity are controlled with this design (Campbell \& Stanley, 1963). In this study, the effect of the instruction with Geogebra towards students' conceptual, procedural knowledge and overall performance on the geometric meaning of derivative and applications of the derivative 
topics was compared to the effect of instruction without using technology with this design.

\subsection{Participants}

This experimental study carried out in two sections of calculus classes. There were total of 55 second grade students enrolled in the department of elementary school mathematics education in the faculty of education in a public university located in the eastern part of Turkey. There were 31 students in one section and 24 students in the other section. The convenience sampling method was utilized to carry out this study (Cohen, Manion, \& Morisson, 2000). Among them, the group with 31 students was randomly assigned as experimental group, in which the Geogebra aided instruction was utilized. The other group with 24 students was assigned as control group, in which their instruction did not included technology use.

Considering the students' background information, they all graduated from the quantitative departments of high schools in Turkey. Regarding Turkish mathematics curriculum, all high school students in the same departments receives the same curriculum. The curriculum for pre-calculus course covers the basic rules in different function types, limit, derivative and integration (Ministry of National Education [MoNE], 2013). Therefore, it was assumed that they have basic knowledge about limit, derivative and integration.

To be enrolled in elementary school mathematics education department in a university, they had to take national wide university entrance exam (over 1.8 million students takes this exam each year). Students were emplaced to the universities according to the score gathered from this exam. Therefore, their exam scores vary only in a small range. In addition, students in the same grade level were randomly assigned to any of the sections due to university policies. Moreover, the midterm exam results ensured that both groups were equivalent in terms of mathematical ability.

\subsection{Data Collection Tools and Procedure}

The main data collection tool used in this study is the Applications of Derivative Test (ADT). It was administered to control and experimental groups as pre- and post-tests. This test involves six open-ended questions, three of which were focusing primarily on procedural knowledge. On the other hand, remaining three questions were mainly focusing on conceptual knowledge. The questions were either adapted from different course books (e.g., Adams \& Essex, 2010; Balc1, 2010) or prepared by the researchers.

The procedural knowledge questions in the ADT were related to max-min problem, finding the tangent line of a function at given point and a problem related to related rates. On the other hand, the conceptual questions in ADT involved the interpretation of graphs of a function and derivative of a functions according to sub-questions asked, and the interpretation of the functions under specific conditions and with properties.

The English version of one of the procedural question in ADT was as follows:

"A rectangle has its two edges on $\mathrm{y}$-axis and line $\mathrm{y}=6$ and one of its corner on curve $\mathrm{y}=\mathrm{x}^{2}$. For all such rectangles, what are the dimensions for the rectangle with largest area?"

The English version of one of the conceptual sub-question in ADT was as follows:

"Given graph of derivative of a function, what are the ranges that the $f(x)$ is concave up?"

Before using the test as data collection tool, a rubric involving the purpose of test, the definitions for procedural and conceptual knowledge and criteria for selecting the questions in line with the purpose proposed was prepared. In this study, the definition for conceptual and procedural knowledge in Star's (2005) study was used in line with the purpose of the study. As it was mentioned, there is no certain boundaries to define which knowledge is conceptual or procedural (Star, 2005; Yanık, 2016). However, students might have greater conceptual knowledge about a specific topic than procedural knowledge or vice versa (Rittle-Johnson et al., 1999). Similarly, the problem solutions can also be mainly relied on either conceptual or procedural knowledge. Therefore, this notion was taken into consideration when selecting the questions asked in the ADT and categorizing them as conceptual or procedural.

The criteria for selecting the questions were whether the questions cover the topics studied, whether the questions were mainly focusing on either procedural or conceptual knowledge, and whether the questions were appropriate for second grade students' mathematical abilities. The rubric and ADT was subjected to two lecturers who had experience in teaching calculus. The final version was prepared and applied according to the experts' recommendations and consensus.

After assigning the sessions as control and experimental groups, both were subjected to ADT for 50 minutes. Each week, the calculus course was four hours per week. The same instructor taught the topic covering the applications of the derivative in three weeks. He asked the same question and did the same applications in both 
sessions. The difference between the sessions during teaching activities were that the instructor solved the questions and did the activities by means of Geogebra. There were more than 15 Geogebra files used during the instructions, two of which were as follows. For example, he presented the geometric meaning of the derivative by relating the derivative formula via Geogebra. He explained how the instant change in the value of $\Delta x$ influences the slope by using the dragging property of Geogebra.

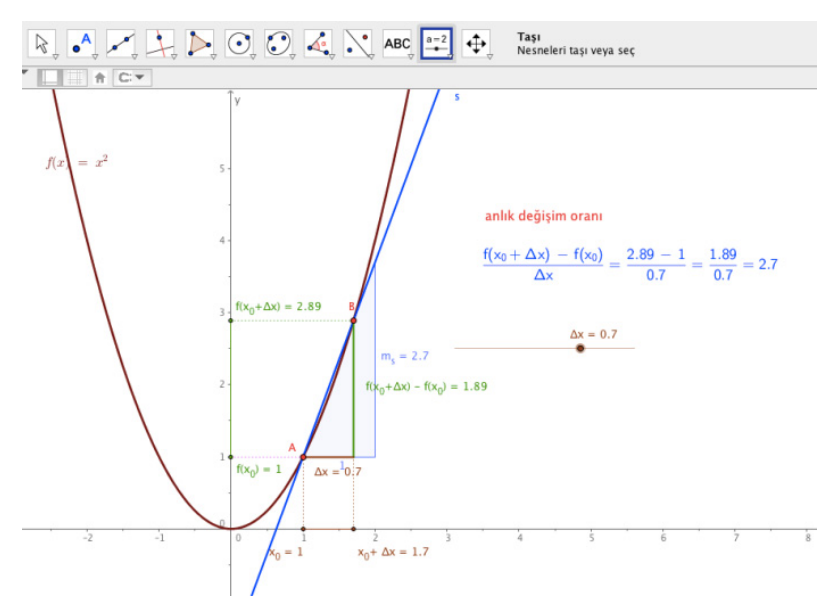

Figure 1. The material used to explain the geometric meaning of derivative for experimental group

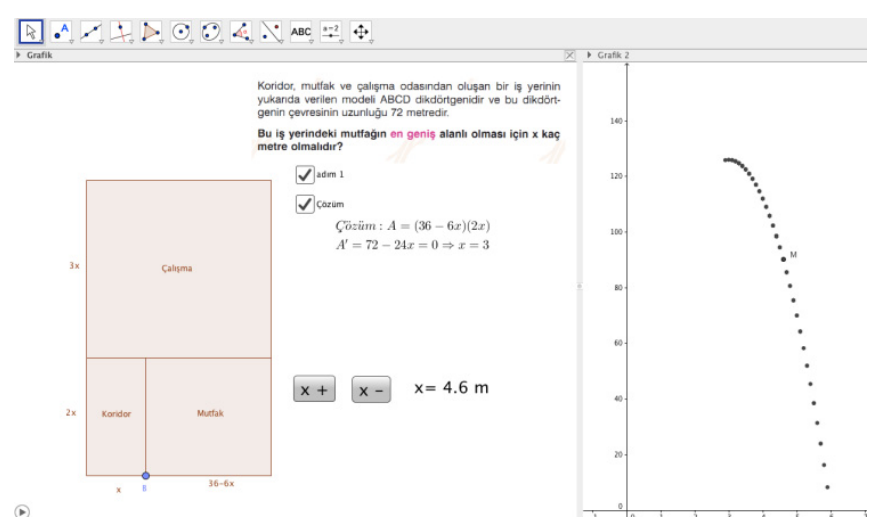

Figure 2. Model presented to students for house plan problem

On the other hand, the lecturer drew the shape and write the derivative formula on the board. Then, he tried to make a relation among the static graph drawn, the slope of function at given point, and the derivative formula. Another example can be given for max-min problem. The instruction solved the house plan problem. Given that the rectangular shaped house has hallway, workroom and square shaped kitchen and its circumference is $76 \mathrm{~m}$, the question was asking to find the value of $\mathrm{x}$, if the house has widest kitchen. With the conditions given in the question, the model for house plan problem was presented to students as in the Figure 2. 


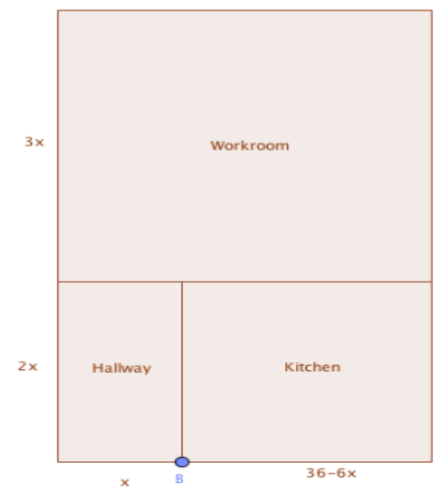

Figure 3. Snapshot of the Geogebra file for modeled house plan problem

In control group's classroom, the lecturer solved the questions by getting help from the presented model on the board. He did the necessary calculations by referring to this model. On the other hand, previously prepared Geogebra file for house plan problem was presented to the students in experimental group' classroom. By dragging the point $\mathrm{B}$ or increasing or decreasing the value of $\mathrm{x}$, he showed the relation between the area of the kitchen on the graph and the value of $\mathrm{x}$. Snapshot of the Geogebra file for modeled house plan problem is shown in the Figure 3. Considering the point $\mathrm{M}$ on the interactive graph connected to house plan shown on the left side of Geogebra snapshot, the $\mathrm{x}$-axis represents the area of the kitchen while $\mathrm{y}$-axis represents the value of $\mathrm{x}$.

The instructor taught the topic covering the geometric meaning of the function, the relation between the graphs of a function and its derivative, max-min problems and related rates for three weeks (12 class hours). At the end, the ADT was again subjected to students as post-test. Students were supposed to complete the test within 50 minutes. The summary of the research design was shown in the Table 1.

Table 1 . The summary of the research design

\begin{tabular}{cccc}
\hline Groups & Pre-test & Intervention & Post-test \\
\hline Geogebra & ADT & Teaching with Geogebra & ADT \\
Control & ADT & Teaching without Geogebra & ADT \\
\hline
\end{tabular}

\subsection{Data Analysis}

The ADT was composed of six questions, three of which were related to conceptual knowledge while the rest were related to procedural knowledge. The assessment rubric for ADT was prepared by two researchers and the lecturer who had experience in teaching calculus course. According to the full consensus between them, each question was graded ranged from 0 to 5.0 point was given for empty or completely incorrect answers. On the other hand, completely correct answers were graded as 5. There was a difference between grading criteria for questions related conceptual and procedural knowledge. A procedural knowledge question, for example, was graded according to the expected steps followed by students. The possible alternative solutions were also considered. On the other hand, a question, for example, related to conceptual knowledge included five sub-questions based on the graphs of derivative of a function. Each correct answer for sub-questions were graded as 1 point. This brought the total score of 5 from this conceptual knowledge question. Therefore, the total score to be gained was 15 for conceptual and procedural knowledge questions separately. The total score to be gained from ADT was 30. Each student's pre- and post-test scores were by both researchers for getting scoring agreements between the scorers (Fraenkel \& Wallen, 1996). Interrater reliability for scorers' observations of students' answers to pre- and post-tests of ADT was found to be $92 \%$ and $87 \%$, respectively, which were under acceptable level (Marques \& McCall, 2005). For the disagreed observations, the scorers discussed and finalized the scoring to reach complete agreement for all observations.

Before beginning to conduct the study, the equivalence of the groups should be satisfied (Büyüköztürk, 2008). Although there were various evidences for the equivalence of the groups, both groups were administered to ADT as pre-test in order to determine whether control and experiment group students' mathematical abilities and knowledge involve any possible difference. To check that the groups were equivalent, the ADT was subjected to 
the students in both groups as pre-test by applying independent samples t-test with $\mathrm{p}=.05$ level of significance (Moore, 1995). For the analyses, SPSS 20 was used. Before the analysis, the assumptions underlying t-test should be met. These are the assumptions of independence, normality and homogeneity of variance (Büyüköztürk, 2008). Since two groups involved different individuals and were independent of each other, the first assumption was met. For the assumption of normality, if the sample sizes were less than 50, the Shapiro-Wilks test should be used (Büyüköztürk, 2008). The sig. values for students' scores in Geogebra and control groups were found to be $\mathrm{p}=.225$ and $.171>.05$, respectively. These results yielded that the second assumption was met. Lastly, the homogeneity of variance was evaluated using Levene's test for equality of variances, in which the sig. value of $\mathrm{p}$ should be higher than $\mathrm{p}=.05$ level of significance to assume that the group variances are equal (Tabachnich \& Fidell, 2007). The Levene's test yielded the sig. value of $p=.826>.05$, which ensured that the variances of Geogebra and control groups students' scores were equal. To control whether the groups were equivalent, the independent samples' t-test result is shown in the Table 2.

Table 2. Independent samples t-test results for Geogebra and control groups students' pre-test scores in ADT

\begin{tabular}{|c|c|c|c|c|c|c|}
\hline Groups & $\mathbf{N}$ & Mean & SD & $\mathbf{t}$ & Df & sig \\
\hline Geogebra & 31 & 3.06 & 1.569 & \multirow{2}{*}{.342} & \multirow{2}{*}{53} & \multirow{2}{*}{$.733^{*}$} \\
\hline Control & 24 & 2.92 & 1.613 & & & \\
\hline
\end{tabular}

$* \mathrm{p}>.05$.

Table 2 indicated that there was no statistically significant mean difference for Geogebra group students' scores $(\mathrm{M}=3.06, \mathrm{SD}=1.569)$ and control group students' scores $(\mathrm{M}=2.92, \mathrm{SD}=1.613) ; \mathrm{t}(53)=.342, \mathrm{p}=.733>.05$. These values implied that the groups are equivalent and the study could be conducted to these groups (Moore, 1995).

Same procedure was applied to students' scores gathered from conceptual and procedural knowledge questions and their overall scores in the post-test application of ADT. The first assumption (assumption of the independence) was already met. The other assumptions (the assumptions of normality and homogeneity of variances) were also met as shown in the Table 3.

Table 3. Shapiro-Wilk Test and Levene's Test results to ensure the assumptions of normality and equality of variances for Geogebra and control group students' scores in post-test of ADT

\begin{tabular}{|c|c|c|c|c|c|c|}
\hline \multirow{2}{*}{$\begin{array}{l}\text { Scores gathered } \\
\text { from }\end{array}$} & \multirow[t]{2}{*}{ Groups } & \multicolumn{3}{|c|}{$\begin{array}{c}\text { Shapiro-Wilk Test } \\
\text { (Assumption of Normality) }\end{array}$} & \multicolumn{2}{|c|}{$\begin{array}{c}\text { Levene's Test for Equality of } \\
\text { Variances }\end{array}$} \\
\hline & & Statistics & Df & Sig. & $\mathbf{F}$ & Sig. \\
\hline Conceptual & Geogebra & .950 & 31 & $.161 *$ & & \\
\hline $\begin{array}{l}\text { Knowledge } \\
\text { Questions }\end{array}$ & Control & .977 & 24 & $.829^{*}$ & .172 & $.680 *$ \\
\hline $\begin{array}{c}\text { Procedural } \\
\text { Knowledge } \\
\text { Questions }\end{array}$ & $\begin{array}{c}\text { Geogebra } \\
\text { Control }\end{array}$ & $\begin{array}{l}.950 \\
.922\end{array}$ & 24 & $\begin{array}{l}.153 * \\
.065^{*}\end{array}$ & 2.861 & $.097 *$ \\
\hline All Questions & $\begin{array}{c}\text { Geogebra } \\
\text { Control }\end{array}$ & $\begin{array}{l}.962 \\
.926\end{array}$ & $\begin{array}{l}31 \\
24\end{array}$ & $\begin{array}{l}.336^{*} \\
.080^{*}\end{array}$ & .147 & $.703 *$ \\
\hline
\end{tabular}

${ }^{*} \mathrm{p}>05$.

Table 3 indicated that all sig. values in Shapiro-Wilk Test were higher than $p=.05$ level of significance for both Geogebra and control group students' scores gathered from conceptual and procedural knowledge questions and all questions in post-test of ADT. Therefore, assumption of normality for independent samples t-test was met (Büyüköztürk, 2008). In addition, Levene's test for equality of group variances revealed that the sig. values of $p$ for groups' scores gathered from conceptual and procedural knowledge questions and all questions in post-test of ADT were also higher than $\mathrm{p}=.05$ level of significance. Therefore, the assumption of homogeneity of variances was also met (Tabachnich \& Fidell, 2007). Therefore, all assumptions underlying independent samples t-test were met. The effectiveness of instruction with using Geogebra on students' learning of conceptual and 
procedural knowledge about the applications of derivative was investigated by using the independent samples t-test (Fraenkel \& Wallen, 1996). Geogebra and control group students' overall scores were also compared by means of the same test in order to see the effectiveness of the instruction with Geogebra on the topic investigated.

\section{Findings}

An independent samples t-test was utilized the compare the effect of instructions with and without using Geogebra. In the comparison, students' scores related to conceptual and procedural knowledge on the applications of the derivative were taken into account. In the analysis, the independent variable was the type of instruction, namely, the instructions with and without using Geogebra (Geogebra and control groups). On the other hand, the dependent variables were students' scores related to conceptual, procedural knowledge and their overall scores gathered from students' response to the ADT as post-test.

First null hypothesis was about whether students' post-test scores gathered from questions investigation students' conceptual knowledge were affected by the type of instructions. The independent samples t-test scores were shown in the Table 4.

Table 4. Independent samples t-test results for Geogebra and control groups students' post-test scores for conceptual knowledge questions in ADT

\begin{tabular}{ccccccc}
\hline Groups & N & Mean & SD & t & Df & sig \\
\hline Geogebra & 31 & 7.26 & 2.503 & \multirow{2}{*}{2.786} & 53 & $.007^{*}$ \\
Control & 24 & 5.33 & 2.590 & & & \\
\hline
\end{tabular}

${ }^{*} \mathrm{p}<.05$

Table 4 indicated that there was a statistically significant difference in the mean scores for students' conceptual knowledge scores from post-tests for the Geogebra group $(M=7.26, S D=2.503)$ and the control group $(M=5.33$, $\mathrm{SD}=2.590) ; \mathrm{t}(53)=2.786, \mathrm{p}=.007<.05)$. Therefore, the first null hypothesis $\left(\mathrm{H}_{01}\right)$ was rejected. This finding showed that the students exposed to the instruction with Geogebra statistically achieved better scores from the questions investigating students' conceptual knowledge in post-test as compared to control group students who were instructed without Geogebra during teaching processes. It was observed that there was 1.99 points difference between the groups' mean scores on the questions related to conceptual knowledge.

Considering Geogebra and control group students' post-test scores for the questions related to procedural knowledge in ADT, the Table 5 showed the results of the analysis. The null hypothesis $\left(\mathrm{H}_{02}\right)$ indicated that there was no statistically significant difference between the means of Geogebra and control group students' procedural knowledge scores.

Table 5. Independent samples t-test results for Geogebra and control groups students' post-test scores for procedural knowledge questions in ADT

\begin{tabular}{ccccccc}
\hline Groups & N & Mean & SD & t & Df & sig \\
\hline Geogebra & 31 & 7.47 & 3.899 & \multirow{2}{*}{1.075} & 53 & $.287^{*}$ \\
Control & 24 & 6.44 & 2.965 & & & \\
\hline
\end{tabular}

${ }^{*} \mathrm{p}>.05$.

According to the Table 5, it was observed that there was only 1.03 mean difference between the Geogebra and control groups students' post-test scores for the procedural knowledge questions. Despite, Table 5 indicated that there was no statistically significant mean difference for the scores gathered from the procedural knowledge questions for Geogebra $(\mathrm{M}=7.47, \mathrm{SD}=3.899)$ and control group students $(\mathrm{M}=6.44, \mathrm{SD}=2.965)$; $\mathrm{t}(53)=1.075$, $\mathrm{p}=.287>.05$. Therefore, the second null hypothesis $\left(\mathrm{H}_{02}\right)$ was accepted. This finding indicated that instruction with Geogebra did not have statistical impact on students' procedural knowledge during learning the topic covering the applications of derivative over the instruction without using Geogebra. 
The last null hypothesis $\left(\mathrm{H}_{03}\right)$ indicated that there was no statistically significant difference between mean post-test scores of Geogebra and control groups. Examining this null hypothesis, Table 6 indicated whether the instruction method using Geogebra was effective on students' learning of applications of the derivative.

Table 6. Independent Samples t-test results for Geogebra and control groups students' overall post-test scores in ADT

\begin{tabular}{ccccccc}
\hline Groups & N & Mean & SD & t & Df & sig \\
\hline Geogebra & 31 & 14.73 & 4.897 & 2.187 & 53 & $.033^{*}$ \\
Control & 24 & 11.88 & 4.658 & & & \\
\hline
\end{tabular}

$* \mathrm{p}<.05$

Similar analysis was conducted for students' overall scores in post-test. The independent samples t-test results indicated that there was a statistically significant mean difference for students' overall scores in Geogebra group $(\mathrm{M}=14.73, \mathrm{SD}=4.897)$ and that in control group $(\mathrm{M}=11.88, \mathrm{SD}=4.658) ; \mathrm{t}(53)=2.187, \mathrm{p}=.033<.05$. Therefore, the last null hypothesis $\left(\mathrm{H}_{03}\right)$ was rejected. This finding revealed that the mean difference between students' overall students' scores in the groups was 2.85. Therefore, students in Geogebra group achieved significantly higher scores in the post-test of ADT compared to those who were taught without using it. This brought the interpretation of that instruction with using Geogebra is significantly better way to teach applications of derivative compared to that without using it.

\section{Discussion and Conclusion}

Comparing experimental and control group students' achievements regarding their conceptual and procedural knowledge and overall scores on applications of derivative subject, the findings of this study revealed three main results. Although there was no significant difference between the groups' mean scores for the questions investigating their procedural knowledge, groups' mean scores differed significantly both for the questions regarding conceptual knowledge and for their overall scores in the post-test of ADT.

From these findings, it was obvious that teaching the application of derivation with Geogebra had significant impact on students' achievement regarding their conceptual knowledge. This situation might be attributed to nature of the subject investigated and the beneficiary characteristics of Geogebra during using in the classroom environment. It was evident that the concepts in the calculus are abstract and students need to deal with formal definitions and proofs (Tall, 1993). Although students are better in follow rules and solution algorithms when dealing with calculus problems, they could not understand the concepts conceptually (Aspinwell \& Miller, 1997). Since the application of derivative requires higher order thinking skills due to the necessity of combining the understanding of the concepts, relating with other forms of the same mathematical structures and interpreting them, they experience difficulties in learning this subject. However, Geogebra involves both CAS and DGE properties. Therefore, students could see the visual forms of abstract algebraic structures in the subject of applications of the derivative. They had opportunities to observe the influence of changes in one from to another. This helped students to make connections between the algebraic and graphical representations, so it eased the interpretation of graphical representation of the functions and/or derivative of functions (Botana \& Valcarce, 2001; Hohenwarter \& Fuchs, 2004). They could also formulate generalizations while dealing with the interpretation of the functions and/or derivative of the functions by means of Geogebra (Artigue, 2002; Y1lmaz, Argün, \& Keskin, 2009). This situation could promote students' conceptual knowledge in the subject of applications of derivative. On the other hand, students relied on static images and formal definitions of derivatives of functions and of their interpretations and more heavily on procedural applications. This could have hardened students' understanding and became an obstacle for students to improve their conceptual knowledge in this topic.

Secondly, teaching this topic with Geogebra had no significant influence on group students' scores regarding procedural knowledge. As known in the literature, students experience difficulties in learning calculus and tend to memorize the facts, definitions and follow algorithms (Aspinwell \& Miller, 1997; Mahir, 2009). Therefore, they generally focus on procedural knowledge to be successful in calculus. Although relying only on procedural knowledge might have limited effect on students' success, there should be balance between conceptual and procedural knowledge in order to meaningfully comprehend the subject studied. From the findings related to students' conceptual and procedural knowledge, it could be concluded that students in both groups were in 
similar achievement levels. In fact, the traditional instructions promote the procedural knowledge (Aspinwell \& Miller, 1997). From the findings, both types of instructional methods had similar effect on students' achievements in learning it $(\mathrm{M}=7.47, \mathrm{SD}=3.899$ for control group receiving traditional intervention and $\mathrm{M}=6.44$, $\mathrm{SD}=2.965$ for experimental group receiving intervention with Geogebra). However, the experimental group students' mean scores were still one point higher than that for control group students. Therefore, there is an evidence that students' procedural knowledge about the applications of derivative could also be improved if the necessary attention was given while preparing and presenting the Geogebra activities focusing on students' procedural knowledge.

Thirdly, the findings indicated that teaching this subject with Geogebra had significant effect on students' overall scores. Comparing the other studies investigating the effectiveness of interventions with Geogebra (e.g., Shadaan \& Leong, 2013; Tatar \& Zengin, 2016; Zengin \& Tatar, 2014; Zulnaidi \& Zakaria, 2012), this finding was an expected result. In addition, similar findings were also found in the studies that other dynamic environment software had positive impact on learning mathematics subjects (e.g., Erbas \& Yenmez, 2011; Furner \& Marinas, 2007; Healy \& Hoyles, 2002). The reason for this finding could be attributed to the opportunities that Geogebra facilitates in the learning environments. As known, the Geogebra provide dynamic and interactive environment. This helps student to make connections between algebraic and graphical representations and interpretations accordingly (Tatar \& Zengin, 2016).

Lastly, the main difference between control and experimental students' overall scores came from their scores regarding conceptual knowledge. It is generally stressed in the literature that students need conceptual knowledge instead of mostly relying on procedural knowledge (e.g., Mahir, 2009; Rittle-Johnson et al., 2001). Therefore, it could be implied that teaching with Geogebra combining both the properties of CAS and DGE had positive impact on students' conceptual knowledge and its effective use should be supported in the mathematics classrooms.

\section{References}

Adams, R. A., \& Essex, C. (2010). Calculus: A complete course (7th ed.). Canada: Pearson Education.

Arslan, S. (2010). Traditional instruction of differential equations and conceptual learning. Teaching Mathematics and its Applications, 29(2), 94-107. https://doi.org/10.1093/teamat/hrq001

Artigue, M. (2002). Learning mathematics in a CAS environment: The genesis of reflection about instrumentation and the dialectics between technical and conceptual work. International Journal of Computers of Mathematical Learning, 7, 245-274. https://doi.org/10.1023/A:1022103903080

Aspinwell, L., \& Miller, D. (1997). Students' positive reliance on writing as a process to learn first semester calculus. Journal of Instructional Psychology, 24, 253-261.

Aydos, M. (2015). The impact of teaching mathematics with Geogebra on the conceptual understanding of limits and continuity: The case of Turkish gifted and talented students (Unpublished master's thesis). İhsan Doğramacı Bilkent University, Ankara, Turkey.

Balc1, M. (2010). Çözümlü matematik analiz problemleri 1. Ankara: BalcıYayınları.

Botana, F., \& Valcarce, J. L. (2001). Cooperation between a dynamic geometry environment and a computer algebra system for geometric discovery. In Computer Algebra in Scientific Computing CASC 2001 (pp. 63-74). Berlin Heidelberg: Springer Inc. https://doi.org/10.1007/978-3-642-56666-0_5

Büyüköztürk, Ş. (2008). Sosyal bilimler için very analizi el kitabı (8th ed.). Ankara: Pegem Akademi.

Campbell, D. T., \& Stanley, J. (1963). Experimental and quasi-experimental designs for research on teaching. In N. Gage (Ed.), Handbook of research on teaching (pp. 171-246). Chicago: Rand McNally.

Cohen, L., Manion, L., \& Morisson, K. (2000). Research methods in education (5th ed.). New York: Routledge Falmer. https://doi.org/10.4324/9780203224342

Dikovic, L. (2009). Applications of Geogebra into teaching some topics of mathematics at the college level. Computer Sciences and Information Systems, 12, 191-203. https://doi.org/10.2298/CSIS0902191D

Erbas, A. K., \& Yenmez, A. (2011). The effect of inquiry-based explorations in a dynamic geometry environment on sixth grade students' achievements in polygons. Computers \& Education, 57(4), 2462-2475. https://doi.org/10.1016/j.compedu.2011.07.002

Fraenkel, J. R., \& Wallen, N. E. (1996). How to design and evaluate research in education (3rd ed.). New York, NY: McGraw-Hill Inc. 
Furner, J. M., \& Marinas, C. A. (2007). Geometry sketching software for elementary children: Easy as 1, 2, 3. Eurasia Journal of Mathematics, Science \& Technology Education, 3(1), 83-91.

Healy, L., \& Hoyles, C. (2002). Software tools for geometrical problem solving: Potentials and pitfalls. International Journal of Computers for Mathematical Learning, 6(3), 235-256. https://doi.org/10.1023/A:1013305627916

Heid, M. K. (1997). The technological revolution and the reform of school mathematics. American Journal of Education, 106(1), 5-61. https://doi.org/10.1086/444175

Hohenwarter, M., \& Fuchs, K. (2004). Combination of dynamic geometry, algebra and calculus in the software system GeoGebra. ZDM Mathematics Education, 20(70), 1-5.

Hohenwarter, M., \& Jones, K. (2007). Ways of linking geometry and algebra: The case of GeoGebra. Proceedings of the British Society for Research into Learning Mathematics, 27(3), 126-131.

Kabaca, T. (2006). Limit kavramının öğretiminde bilgisayar cebir sistemlerinin etkisi (Unpublished doctoral dissertation). Educational Sciences Institute, Gazi University, Ankara, Turkey.

Karasar, N. (2009). Bilimsel araştırma yöntemleri (19th ed.). Ankara: Nobel Yayınları.

Kepceoğlu, İ. (2010). Geogebra yazılımıyla limit ve süreklilik ögretiminin öğretmen adaylarının başarısına ve kavramsal ögrenmelerine etkisi (Unpublished master thesis). Educational Sciences Institute, Marmara University, İstanbul, Turkey.

Mahir, N. (2009). Conceptual and procedural performance of undergraduate students in integration. International Journal of Mathematical Education in Science and Technology, 40(2), 201-211. https://doi.org/10.1080/00207390802213591

Marques, J. F., \& McCall, C. (2005). The application of interrater reliability as a solidification instrument in a phenomenological study. The Qualitative Report, 10(3), 439-462.

Meltzer, D. E. (2002). The relation between mathematics preparation and conceptual learning gains in physics: A possible "hidden variable" in diagnostic pretest scores. American Journal of Physics, 70(12), 1259-1268. https://doi.org/10.1119/1.1514215

Milli Eğitim Bakanlığı [Ministry of National Education] (MoNE). (2011). Ortaöğretim matematik dersi ögrretim programı. Ankara: MEB Yayınları.

Moore, D. S. (1995). The basic practice of statistics. New York, NY: Freeman and Co.

Rittle-Johnson, B., Siegler, R. S., \& Alibali, M. W. (2001). Developing conceptual understanding and procedural skills in mathematics: An iterative process. Journal of Educational Psychology, 93(2), 346-362. https://doi.org/10.1037/0022-0663.93.2.346

Samur, H. (2015). The effect of dynamic geometry use on eight grade students' achievement in geometry and attitude towards geometry on triangle topic (Unpublished master's thesis). The Graduate School of Social Sciences, Middle East Technical University, Ankara, Turkey.

Öçal, M. F. (2017). Asymptote misconception on graphing functions: Does graphing software resolve it? Malaysian Online Journal of Educational Technology, 5(1), 21-33.

Öçal, M. F., \& Şimşek, M. (2017). Pre-service mathematics teachers' opinions about FATİH Project and technology use in mathematics education. Turkish Online Journal of Qualitative Inquiry, 8(1), 91-121. https://doi.org/10.17569/tojqi.288857

Pierce, R., \& Stacey, K. (2011). Using dynamic geometry to bring the real world into the classroom. In L. Bu, \& R. Schoen (Eds.), Model-centered learning (pp. 41-55). The Rotterdam, the Netherlands: Sense Publishers. https://doi.org/10.1007/978-94-6091-618-2_4

Shadaan, P., \& Leong, K. E. (2013). Effectiveness of using Geogebra on students' understanding in learning circles. Malaysian Online Journal of Educational Technology, 1(4), 1-11.

Star, J. R. (2005). Reconceptualizing procedural knowledge. Journal for Research in Mathematics Education, 36, 404-411.

Tabachnick, B. G., \& Fidell, L. S. (2007). Using multivariate statistics (5th ed.). Needham Heights, MA: Allyn \& Bacon.

Tall, D. (1993). Students' difficulties in calculus. In C. Gaulin et al. (Eds.), Proceedings of Working Group 3 on 
Students' Difficulties in Calculus, 7th International Conference on Mathematicaal Education (pp. 13-28). Québec, Canada.

Tatar, E. (2012). The effect of dynamic mathematics software on achievement in mathematics: The case of trigonometry. Energy Education Science and Technology Part B: Social and Educational Studies, 4(1), 450-468.

Tatar, E., \& Zengin, Y. (2016). Conceptual understanding of definite integral with Geogebra. Computers in the Schools, 33(2), 120-132. https://doi.org/10.1080/07380569.2016.1177480

Yanık, H. B. (2016). Kavramsal ve işlemsel anlama. In E. Bingölbali, S. Arslan, \& Zembat, İ. Ö. (Eds.), Matematik eğitiminde teoriler (pp. 101-116). Ankara, Turkey: Pegem Akademi.

Y1lmaz, R., Argün, Z., \& Keskin, M. (2009). What is the role of visualization in generalization processes: The case of preservice secondary mathematics teachers. Humanity \& Social Sciences Journal, 4(2), 130-137.

Zengin, Y., \& Tatar, E. (2014). The teaching of polar coordinates with dynamic mathematics software. International Journal of Mathematical Education in Science and Technology, 46(1), 127-139. https://doi.org/10.1080/0020739X.2014.904529

Zulnaidi, H., \& Zakaria, E. (2012). The effect of using Geogebra on conceptual and procedural knowledge of high school mathematics students. Asian Social Science, 8(11), 102-110. https://doi.org/10.5539/ass.v8n11p102

\section{Copyrights}

Copyright for this article is retained by the author(s), with first publication rights granted to the journal.

This is an open-access article distributed under the terms and conditions of the Creative Commons Attribution license (http://creativecommons.org/licenses/by/4.0/). 